\title{
El discurso en práctica: las estrategias de implicación de una institución educativa ante el crimen de una de sus estudiantes*
}

\author{
Silvia Noemí Sánchez*
}

\section{Resumen}

Este artículo indaga las estrategias de implicación desplegadas por los miembros de la comunidad educativa del Instituto de Nivel Terciario Juan Mantovani de la ciudad de Presidencia Roque Sáenz Peña, Chaco, Argentina, ante el asesinato de una de sus estudiantes. La implicación, que es el involucramiento de una persona con la tarea o rol que desempeña, es estudiada a través de seis entrevistas a diferentes actores institucionales seleccionados por su rol: directivos, docentes y estudiantes. El análisis de estos discursos permite echar luz sobre el carácter articular y transicional de las prácticas educativas, a la vez que hace evidente el potencial creativo e instituyente de las relaciones institucionales.

\footnotetext{
* Artículo recibido el 28 de junio de 2014. Aceptado el 12 de septiembre de 2014.

* Silvia Noemí Sánchez es docente en la Facultad de Artes, Diseño y Ciencias de la Cultura de la UNNE, investigadora integrante del proyecto de investigación "La incidencia de las ideas matemáticas y las nociones sobre la realidad natural del contexto sociocultural en la educación universitaria" (PI №30-UNCAUS, 2012-2016). Candidata a magíster en Ciencias Sociales y Humanidades con mención en Comunicación por la UNQ. Tesis titulada: "Las matemáticas en el trabajo manual de costureras y albañiles. La comunicación y el aprendizaje en ámbitos informales". Correo electrónico: silvi_060378@hotmail.com
} 


\section{Palabras clave}

Institución educativa - Análisis del discurso - Prácticas sociales Implicación.

\section{Abstract}

This paper investigates the implication strategies used by members of Institute of higher education Juan Mantovani -in Presidencia Roque Sáenz Peña, Chaco, Argentina- through the speech of some of the educative community members concerning with a student's murder. Implication that means a person involvement with their own work or roles, be study in six interviews -an institutional different actors selected by their roles: managerial, teaching, y, student. This analysis allows understand on character articulate transitional and of educational practices, and manifest the creative possibilities of the institutional relations.

\section{Keywords}

Educational institution - Discourse analysis - Social practices Implication.

\section{Introducción}

El interés de este trabajo radica en investigar las estrategias de contención puestas en funcionamiento por una institución educativa al ver interrumpida su dinámica cotidiana por el crimen una de sus alumnas [1]. La aprehensión y comprensión de este hecho no escapa a la especificidad de lo institucional, por ello, en un intento metodológico por recoger la polifonía discursiva de las personas que conforman lo institucional se realizaron seis entrevistas a diferentes actores [2]. No obstante, se privilegió -para la contextualización y el análisis de las prácticas institucionales- una entrevista concedida por Mirian Cano [3], la ex rectora de la institución escolar, en su domicilio particular a dos años aproximadamente de los hechos que ocasionan la indagación [4]. Su discurso se interpreta en función de los desarrollos teóricos de Norman Fairclough (1992). Las restantes entrevistas -analizadas desde el enfoque de análisis e intervención institucional de René Loureau (1975), Marta Souto y Lucía Garay (1993), Eugène Enriquez (2002)- se utilizarán complementariamente en la comprensión del proceso de implicación institucional. 
La investigación se ubica contextualmente en la comunidad educativa del Instituto de Nivel Terciario "Juan Mantovani" [5] de la ciudad de Presidencia Roque Sáenz Peña Provincia de Chaco, que en el año 2010 vio conmovida su labor habitual por el asesinato de una de sus alumnas del $4^{\circ}$ año del Profesorado en Inglés, Maira Alejandra Tévez [6]. La estudiante fue ultimada en las cercanías de la institución, en la pensión en la que residía temporariamente para cursar sus estudios. El caso tomó estado público y conmocionó a la comunidad saenzpeñense por su virulencia, ya que la joven fue desmembrada y sus restos fueron esparcidos por la ciudad.

El instituto terciario tuvo un protagonismo destacado desde el primer momento; sus autoridades, alumnos y docentes encabezaron marchas multitudinarias por las calles de la ciudad en pedido de justicia y seguridad, se organizaron misas y charlas reflexivas en la sede institucional y se confeccionaron carteles y pasacalles con la foto de Maira Tévez (en adelante M.T.) que fueron distribuidos en distintos puntos de la ciudad.

El caso fue resuelto por la justicia local con relativa rapidez, ya que el asesino fue prontamente identificado, procesado y condenado.

\section{Marco teórico-metodológico}

Si un texto "es un entramado compuesto de muchas hebras diferentes portadoras de significado que actúan de manera simultánea" (Eggins \& Martin, 2003: 339) debemos reconocer no solo que todo discurso trata de más de un asunto a la vez, sino que su enunciación posiciona a su autor en una red de relaciones específicas propias de su entorno inmediato -el contexto de situación- y mediato -el contexto de cultura-, y también deja en evidencia sus actitudes hacia el tema abordado y su relación para con sus interlocutores, es decir, los significados interpersonales del texto.

El lenguaje es un potencial de significados compartidos que conforma la experiencia y su interpretación intersubjetiva (Halliday, 1978) por ello, explicitar las distintas hebras de significación que se entrecruzan en todo entramado textual y explicar su correlación contextual, puede echar luz sobre los complejos mecanismos y estrategias de los que se valen las instituciones, a través de sus actores, ante situaciones particularmente extremas. Se trata, entonces, de reconstruir intersubjetivamente a partir de un relato de vida parcial el grado de implicación que el sujeto emprendió ante una experiencia violenta que marcó tanto su subjetividad como la dinámica institucional en la que se hallaba inmerso.

La dificultad para aprehender la noción de institución -como formación cultural que es a la vez 'marco externo' y 'contención interna' encubierta en los pliegues de la ideología y matizada por las construcciones fantasmáticas (Fernández, 2002)- será abordada desde las cuatro notas con las que Eugene Enríquez (2002) la define: 1) la institución es lo que da el comienzo, lo que establece y lo que forma; 2) el saber y las prácticas que se derivan de lo institucional "no debe ser simplemente un modo de instaurar las cosas sino que debe penetrar en lo más profundo de nuestro ser" 
(Enríquez, 2002: 54); 3) todas las instituciones giran en torno a una persona que ocupa un lugar central y toda institución plantea entonces el problema de la paternidad y la filiación, y 4) por su existencia, desde su establecimiento, las instituciones tienden a reproducirse.

A diferencia de las organizaciones productivas, los espacios de la educación y la formación deben ser "instituciones de vida" donde el otro importa como persona no solo en su dimensión cognitiva, sino considerándolo con y en sus condiciones tal como ellas se presentan. Deben ser además espacios de formación a través del vínculo intersubjetivo y la toma de conciencia sobre uno mismo y los procesos externos. Por último, deben ser espacios donde cada sujeto "deviene en lo que va siendo" por la comprensión del mundo, pero también y fundamentalmente por el conjunto de identificaciones desde las cuales se accede al conocimiento del entorno y de uno mismo (Fernández, 2002).

El concepto de prácticas entendidas como las "maneras 'habituales' ligadas a tiempos y espacios habituales, en las cuales las personas utilizan recursos (materiales, simbólicos) para actuar juntos en el mundo" (Chouliaraki \& Fairclough, 1999) es una noción clave que permite la conexión entre estructuras abstractas y eventos concretos que se analizan en "coyunturas", es decir, conjuntos relativamente estables de prácticas alrededor de proyectos sociales que pueden atravesar y reunir distintas instituciones. El discurso articula en un doble sentido las prácticas ya que las estas son parcialmente discursivas y a la vez son discursivamente representadas. $Y$ una de las principales propiedades de los discursos es la de "joint action", o sea, su potencial creativo en la interacción social.

Los enunciados, en cuanto unidades de análisis del flujo discursivo, son un fenómeno enteramente sociológico. El potencial creativo del lenguaje se concreta en la interacción discursiva de los hablantes, y por lo tanto no puede ser comprendido separado de los sentidos y los valores ideológicos (Volóshinov, 2009) que la coyuntura social le otorga en cada momento, de allí la importancia de un abordaje dialéctico y dialógico de cada realización discursiva.

Para este trabajo se adoptará el concepto de implicación que proviene de los enfoques de análisis e intervención institucional. René Loureau lo define como "el conjunto de relaciones, conscientes o no, que existen entre el actor y el sistema institucional" (Loureau en Souto, 1993: 81). En la misma línea, Marta Souto lo explica apelando a la etimología: "implicar" deriva del latín "im-plicare, im-plico", "enlazar, enredar, entrelazar, envolver dentro". Y también sostiene que "otras acepciones del diccionario agregan 'contener, llevar en sí, significar'. "La implicación es 'lo contenido en una cosa', también 'el estado de la persona envuelta en'" (Souto, 1993: 84). La implicación, entonces, es el involucramiento de una persona o grupo con la tarea o rol que desempeña, es la "relación en la que ambas partes se entrelazan y envuelven 
mutuamente, generando una red que se entrecruza con lo ya existente" (Souto, 1993: 84).

Las instituciones, en particular las educativas, son portadoras a través de su lenguaje, de sentidos y significados específicos de la sociedad, no como instancias históricosociales, sino como instancias singulares de prácticas, de tareas, de intervenciones. "Los sujetos intervienen y constituyen las instituciones en la trama de relaciones -sociales, laborales- y vínculos -relaciones investidas de afectos-“(Garay, 1993: 132).

Complementariamente, se valorará, siguiendo a E. Laclau y C. Mouffe (2004: 148), "el carácter relacional y precario de toda identidad" cuyo discurso se ve profundamente articulado como resultado de una práctica que también posee carácter simbólico y por ello es estructurante y atraviesa el espesor material de las instituciones. Este flujo contingente y ambiguo impide la fijación de significados últimos, permitiendo la formulación de significados parciales que resulta del desborde constante de todo discurso por la infinitud del campo de la discursividad.

Por último, para el análisis se privilegió una metodología cualitativa, se tomaron seis entrevistas en profundidad a diferentes actores institucionales seleccionados en función de sus roles institucionales específicos: dos autoridades, dos docentes y dos estudiantes. El protagonismo y compromiso manifiesto de la ex rectora, M.C. -que era guía y máxima responsable de la institución al momento de los hechos- ha hecho que su discurso fuera seleccionado particularmente para el análisis del contexto y de las prácticas. No obstante, para la descripción de las diferentes estrategias de implicación que la institución tejió a raíz de los hechos, se recurrió alternativamente a las voces de los distintos actores institucionales.

\section{Los discursos en contexto}

En primer lugar, pondremos de relieve las características del contexto social en el cual se produjeron los discursos que hemos de analizar, ya que la estructura léxicogramatical de los textos se ve influida por este. El contexto de cultura, "similar al concepto de 'experiencia y saber del género humano' de Firbas" (MontemayorBorsinger, 2009: 81), comprende todo el sistema semántico del lenguaje, el trasfondo cultural amplio que permite interpretar y dar sentido a lo que se hace como lo que se dice (Ghio \& Fernández, 2005). El contexto de cultura engloba al contexto de situación, más particular, entendido como "todos los factores extralingüísticos que tienen importancia en el texto mismo" (Ghio \& Fernández, 2005: 26). Así, dado un contexto de cultura, los hablantes usan la lengua de manera más específica en lo que se denomina contextos de situación.

El contexto de cultura en el cual se inscribe la entrevista realizada a M.C. -ex rectora del INTJM de Pcia. Roque Sáenz Peña- comprende el conjunto de saberes y convenciones respecto de lo que representan las autoridades educativas en nuestro país. La docencia es una actividad asociada generalmente a lo femenino y a la 
maternidad (Lobato, 2007; Barrancos, 2007). Los cargos directivos en las instituciones educativas suelen estar revestidos de mayor o menor prestigio y autoridad, según la trayectoria histórico-institucional de quienes hayan detentado el cargo. Los rectores son los principales responsables de la formación de los futuros maestros y profesores en los institutos de educación superior por lo que la importancia de su función es primordial en la organización jerárquica de los sistemas educativos, en la toma de decisiones, en los estilos y hábitos asociados con el desempeño del rol docente. M.C., la entrevistada, ejerció el cargo de rectora por 20 años en el mencionado establecimiento. Ya jubilada accedió a la entrevista y se mostró gustosa de aportar sus recuerdos y visión personal de los hechos; ello da cuenta del compromiso e identificación que aún siente con la labor docente y de gestión que desempeñó.

El tema en torno al cual giró la conversación fueron los recuerdos de su accionar personal e institucional a raíz de la conmoción ocasionada por el asesinato de la alumna M.T. Este feminicidio conmovió la calma cuasi pueblerina en la que se desenvuelven las relaciones cotidianas entre los vecinos de Pcia. R. Sáenz Peña por su crueldad, puesto que la víctima fue descuartizada y sus miembros esparcidos por distintos puntos de la ciudad. Los presupuestos sobre la violencia de género, la psicopatía homicida, los motivos del crimen, el reclamo por justicia, la falta de condena a los culpables de delitos contra las mujeres, etc. constituyen los otros elementos del contexto de cultura que enmarcaron el intercambio discursivo.

En cuanto al contexto de situación, la entrevista fue solicitada telefónicamente y concertada a la brevedad en el domicilio particular de M.C. El evento social que se constituyó fue una entrevista profunda, precedida de una charla informal en la que la entrevistadora informó acerca de los motivos por los cuales se solicitaba la entrevista, y que se cerró con la promesa de compartir el trabajo final.

El grado de familiaridad con el tema que cada una de las interlocutoras supone que la otra posee, y el vocabulario cotidiano y en confianza que se utiliza dan cuenta de las características del evento social y su contexto. En el primer enunciado extraído a continuación, por ejemplo, se usa la expresión "bobazo" por "infarto" debido a que el intercambio es informal y de confianza; en el segundo, se interroga a la entrevistadora si recuerda un dato que se presupone compartido:

"...Entonces, 'Yo no lo quiero exponer a mi papá porque le puede dar un bobazo', ¿viste?, decía ella..." (M.C., 11/09/2012)

"-Y claro, tenían que unirlo para ver si era ella, ¿viste? Sí, bueno, si en realidad era todo de ella, ¿viste? Y bueno lo unieron y bueno, ¿te acordás lo de la cabeza que fue macabro?, bueno, este... Pero el tipo, este... hacer semejante..." (M.C., 11/09/2012) 
Las participantes de la interacción fueron: la entrevistada, M.C., y, la entrevistadora, Silvia N. Sánchez [7]. Entre ambas existe una relación previa [8] y mantienen un intercambio de respeto, de reconocimiento y de cordialidad.

El rol discursivo que desempeñó M.C. fue de entrevistada, testigo de los hechos y protagonista del relato, ya que ocupaba el cargo de Rectora del INTJM al momento del crimen. El rol discursivo de S.N.S. fue el de entrevistadora, quien prácticamente se limitó a escuchar y registrar el relato, puesto que el devenir enunciativo surgió espontáneamente. Se generó un clima de confianza entre ambas -seguramente producto de la relación previa y al hecho de que M.C. ya no desempeña el cargo directivo- lo que permitió que M.C. diera cuenta en profundidad de sus recuerdos y valoraciones de los hechos sin intervenciones notorias por parte de S.N.S. La actitud de las interlocutoras entre sí fue colaborativa. Respecto de sus discursos, M.C. trataba de recordar de modo ordenado los hechos, hacerlos entendibles; S.N.S. trató de intervenir lo menos posible, aunque en breves enunciados valoró los hechos.

El lenguaje usado ilustra los papeles del discurso por medio de los roles sociales: en el fragmento que se extrae a continuación, se observa cómo M.C. juzga que el crimen fue perpetrado por un psicópata, un desequilibrado, sintetizando y condensando su juicio con la expresión "icómo lo van a dejar a él!", en el que se superponen dos voces y dos conciencias en intertextualidad:

"...pero yo digo que el tipo es un psicópata, ¿viste? Consciente de lo que hace -por supuesto-, pero sin culpa alguna, ¡cómo lo van a dejar a él!, ¿viste?..." (M.C., 11/09/2012)

Es interesante detenernos en la significación polifónica resultante. La entrevistada manipula el discurso o conciencia ajena contraponiendo de esta suerte dos sistemas de valores; la palabra "toma distancia" a través de la ironía y deja de identificarse con la voz emisora para contraponer la conciencia del autor del crimen. Podríamos decir junto con E. Laclau y C. Mouffe que toda identidad se constituye en articulación, es incompleta en sí misma, y se estabiliza parcialmente desde múltiples posiciones sociales produciendo efectos diversos.

Estas posibilidades de manipulación de la voz propia y ajena que ofrece el lenguaje se corresponden a su vez con la fuerza de la ideología dominante en determinadas condiciones socio-históricas que persisten aún ante la evidencia de perspectivas plurívocas de la realidad (Volóshinov, 2009; Ponzio, 2003). La voz ajena se trasmite y orienta hacia un tercero, en este caso la entrevistadora. $Y$ esta orientación es relevante porque "consolida la influencia de las fuerzas sociales organizadas sobre la percepción discursiva" (Volóshinov, 2009: 184). Así, entre el discurso ajeno y su contexto que lo actualiza prevalecen relaciones tensas y complejas. Obsérvese que M.C. utiliza irónicamente la voz ajena como corolario ratificador del devenir de su argumentación. La economía de recursos lingüísticos obtenida y su condensación semántica es 
sorprendente, la voz ajena se incrusta en el propio discurso y su contundencia hace accesorias otras explicaciones.

En otro enunciado, vemos cómo M.C. valora el grado de conmoción que le causó el crimen de la alumna en relación con otro drama que marcó la historia del país, el caso de María Soledad Morales, y lo vincula, además, con sus veinte años de ejercicio del cargo directivo [9]:

"...Mirá que pasaron cosas que si uno se pone a escribir un libro, pero acordáte que yo estuve veinte años al frente de esa Rectoría... Pasaron cosas, miles de cosas, pero esa, eso fue algo, ya lo máximo, no debe haber ocurrido en ningún lado... Mirá que lo de María Soledad, que también se hizo institucional, fue el impacto y todo lo demás y fue a nivel nacional por quienes estaban involucrados que eran hijos del poder, ¿viste? Acá no, acá era un pilincho más, pero acá impactó lo que hizo con esta chica. A María Soledad la maltrataron, la mataron, pero no se ensañaron, o sea, se han ensañado de otra manera, pero este impacto de querer desparramar el cuerpo. ¿Qué quería?, ¿viste? Y bueno, eso es lo que me acuerdo a grandes líneas..." [10] (M.C., 11/09/ 2012)

El hecho relatado es inscripto en la memoria personal con sus contradicciones, hibridaciones, marchas y contramarchas, esa memoria que contextualiza en función de sus coordenadas vitales compara y re-interpreta en la búsqueda de sentidos, negándose a una sutura esencialista y vertical que cierre el diálogo entre pasado y presente.

A continuación se extrae un enunciado en el que se subraya la valoración que M.C. hace sobre una de las preguntas hechas por S.N.S. previamente, dando cuenta de cómo estima la intervención de su interlocutora. El tema del fragmento es el rol de la madre de la víctima:

"...ella estaba en las misas, no, en las marchas, no estuvo, porque esa señora dice que quedó muy mal, pero sí, en las misas estaba y ella agradecía, solamente agradecía la presencia, la... Está bien esa pregunta, porque la mamá, el rol de la mamá, hasta en esas situaciones, ¿viste? Seguramente que era la que más sufría, digo, porque perder a un hijo, y sin embargo ella se mantuvo a la sombra de la hija y del padre." (M.C., 11/09/2012)

\section{El discurso en práctica}

Veremos a continuación el tipo de estructura del texto que simultáneamente construye un modelo de la experiencia, representa las interacciones sociales y crea un texto relevante:

"...de Pampa del Infierno. El domingo vinieron los papás, mejor dicho el padre y la hermana mayor... Y, bueno, ahí te puedo decir que... ¿vos me decías cómo actúa, cómo actuamos nosotros como gestores institucionales? A mí se me acabaron los libros, yo no sabía ni 
qué decir; no, no sabía qué hacer con esa familia y peor fue cuando el padre me dijo: “Me la hubieran matado, pero no tirado..., por qué me la tiraron la cabeza a los perros", ¿viste? Y eso me... me... me... mató, ¿viste? No, no, en serio que no sabés qué decir y optás por el silencio, por el apretón de la mano, y bueno, y llorando junto con ellos... No hay otra, yo creo en ese momento no me salió otra cosa, ¿viste? Lo que sí ya cuando nos calmamos un poco, le dije a la hermana sobre todo porque el padre estaba devastado, le dije a la hermana que cuente con la institución para lo que necesite, para lo que necesite, dinero, apoyo, apoyo para la búsqueda de quién era -porque hasta ese momento no sabíamos quién era el asesino- y bueno y así quedamos, así quedamos... Después este... Te, te termino la línea familiar digamos, ¿no?" [11] (M.C., 11/09/2012)

Seleccionamos para el análisis el enunciado subrayado. Siguiendo a MontemayorBorsinger (2009), este se encabeza con un sujeto psicológico, tema de la oración, seguido de la referencia del sujeto gramatical objeto, los libros; la ausencia de un sujeto lógico, esto es que realiza la acción, confiere al enunciado un carácter impersonal, desdibujándose en la expresión la causa que origina el proceso: "A mí se me acabaron los libros...".

Es decir, el hecho arrastró consigo la experiencia de la enunciadora, el proceso se presenta en su crudeza dando cuenta de su condición inerme, ya que sobre ella recae la acción. El sujeto psicológico "A mí", es el punto de partida del mensaje, considerado tema, es el arranque del ordenamiento de significados de la cláusula donde las dos inteligencias, la del locutor e interlocutor se encuentran (Montemayor-Borsinger, 2009).

En la siguiente proposición: "...yo no sabía ni qué decir; no, no sabía qué hacer con esa familia..." El sujeto "yo" es tanto lógico -el que verdaderamente hace la accióncomo gramatical -el que gobierna el verbo. El sujeto es la enunciadora que no sabe, en primer término, lo que debe decir, no logra encontrar las palabras adecuadas, y en segundo término, no sabe qué hacer, qué acciones realizar "con esa familia", que es, en la oración, el complemento circunstancial. Se orienta la acción en primer lugar hacia la familia, considerada el grupo humano más vulnerable en ese momento -al enterarse del asesinato.

El horror se acrecienta al final de la oración: "... y peor fue cuando el padre me dijo..." Aquí, el sujeto de la proposición está omitido, puede inferirse que hace referencia a la situación; el verbo es copulativo y su carga predicativa se anticipa con "peor"; el estilo directo señala el clímax del horror, que trae, actualiza, y presenta en su crudeza las palabras del padre de la víctima quien, entre resignado e impotente, busca explicaciones imposibles: "Me la hubieran matado, pero no tirado... por qué me la tiraron la cabeza a los perros".

En ese momento la enunciadora hace una pausa en su relato para interpelar a quien la escucha, verificar si es escuchada, constatar si esta asiente o disiente: "¿viste?" 
El remate del enunciado se da en una oración en la que la situación anteriormente relatada es referida a través del pronombre demostrativo "eso", sujeto gramatical, la acción enunciada por el verbo recae directamente sobre la enunciadora "me mató", equiparándose su situación imaginaria con la de la víctima del homicidio, M.T. El enunciado se cierra, finalmente, con la interpelación reiterada a su interlocutora, propia de la oralidad: "...Y eso me... me... me... mató, ¿viste?".

\section{La implicación institucional}

La implicación de los miembros de la comunidad educativa se evidencia en las seis entrevistas realizadas. En varias de ellas se alude al campo semántico de la 'familia', la institución es 'lo familiar', 'lo querido', 'lo cercano y conocido'. Así, ante el interrogante sobre qué hizo el INTJM al conocerse la noticia, una de las docentes expresó:

"Acá [en el instituto] tuve esa sensación de muerte tan dolorosa así como si fuese algo, alguien -realmente lo era- alguien de la familia. Se sintió, yo sentí eso, ese desconsuelo. ¿Qué hizo? Fue esa urgencia de unirnos de ir a la marcha de sentirlo así como la pérdida de un ser querido". (B.S., 15/08/2013)

Una estudiante que por entonces cursaba el ler año del Profesorado en Educación Primaria manifestó:

"Ellos [los profesores] decían que eran como una familia, la institución, eso me acuerdo perfectamente. Los profesores, la rectora en ese momento también decía que ellos estaban muy afectados porque no eran simplemente alumnos y profesores, sino ellos eran como una familia todos juntos". (Z.P., 12/07/2013)

También es frecuente en las docentes la identificación con el dolor del otro y con el rol de madre:

"...se notó muchísimo el sacudón que fue, fue muy intenso y así esa, yo te lo podría actuar, pero ¡no lo podíamos creer!, y empezamos a salir y eso de juntarnos con las marchas de las velas, lo de las velas era [hace el gesto de escalofrío], ¿viste? Como madre de dos hijas mujeres, que soy, que están lejos, y me cuesta y yo les contaba eso a ellas y me involucro enseguida y me hace bolsa la madre ahí con, costaba mucho, a todos nos costó...". (BS, $15 / 08 / 2013)$

Ante el dolor que se hace insoportable, las palabras parecen no ser suficientes, o perder su capacidad explicativa, de allí la necesidad de "poner el cuerpo":

"Mi recuerdo de las marchas... Una de ellas terminó en la Iglesia y me conmovió el llanto de los padres, de los hermanos, de todo su entorno familiar. Y yo lo que me preguntaba qué les 
podés decir, ¿viste? Lo que vos le digas no va a ser suficiente porque no es algo natural, entonces para mí fue darle un abrazo, un beso, un apretón, para mí...". (TS, 09/08/2013)

"...optás por el silencio, por el apretón de la mano, y bueno y llorando junto con ellos...".(M.C., 11/09/2012)

Otro aspecto interesante que surgió en la entrevista a la actual rectora del INTJM, R.G., fue el esfuerzo de los miembros de la institución por volver a la normalidad, al orden, allí donde percibían una situación anormal. Resulta gráfica la narración de una escena que aconteció antes del crimen, pero que se vincula directamente con este:

"Un día, uno de los bedeles me avisa que había una persona desconocida en el gabinete de Informática utilizando una de nuestras computadoras. Yo me arrimo y estaba este muchacho, Ponce, usando una computadora; entonces, yo entro y le digo: '¿Ponce, vos qué estás haciendo acá?' Y me dice que él estaba haciendo un trabajo a su novia, ayudándola. Entonces, le dije que (...) él no era alumno, no era profesor, no era absolutamente nadie para estar ahí, que inmediatamente le daba dos segundos para que se retirara de ahí, si no iba a llamar a la policía porque estaba usando instalaciones institucionales que no le correspondían. Entonces, medio de mal humor se fue...". (R.G., 26/08/2013)

R.G. conocía a Ponce -el inculpado- porque había sido su alumno en otra institución en la que cursaba Enfermería universitaria. Lo recuerda como un hombre "problemático" no solo por sus actitudes hacia sus compañeros y hacia los docentes, sino que "había inconductas de él que no se condicen con el código ético del enfermero". Al identificarlo como un sujeto ajeno a la institución, que podría generar una disrupción en la vida académica, no dudó en exhortarlo a que se retirara del predio. Su intervención traza los límites, instaura cierta regulación social que asegura la convivencia y la trasmisión educativa. R.G. asume con su conducta una dimensión axiológica que la compromete en la recomposición del orden alterado.

La conmoción por el crimen de M.T. fue tan intensa, que varios miembros admiten que durante un tiempo fue menester interrumpir la función estrictamente escolar:

"...era mi alumna en ese momento. Yo había dictado clases el miércoles y esto ocurrió un viernes a la noche, sábado a la madrugada, creo, y todos quedamos shockeados [...] La semana siguiente no hubo clases porque seguía toda esta cuestión, sus compañeros estaban acongojados con la noticia, alguien con quien estás compartiendo cuatro o cinco años de todos los días de ir a cursar, de repente no está, no es lo mismo que se despida y se vaya por una causa que no tiene raciocinio, ¿viste?". (T.S., 09/08/2013)

"No podíamos tener clases porque todos llorábamos, la angustia, el miedo, fue tremendo...". (M.G., 13/07/2013) 
"Durante varios días no dio clases ese curso porque obviamente no los íbamos a poner en una actividad académica después de semejante shock, así que no solamente fue al momento de enterarnos, sino que por meses...". (R.G., 26/08/2013)

Por último, entre las estrategias de contención y acción institucional que se evidencian en las diferentes entrevistas realizadas podemos mencionar:

- Las distintas acciones de salida de la institución fuera de su ámbito locativo específico, el edificio escolar, extendiendo su función específica, lo educativo, para reclamar y hacer público el dolor por la muerte de uno de sus miembros:

"Hicimos la primera marcha y eso hizo que la gente de la Justicia es como que se ha apurado para esclarecer porque fue muy rápido...". (M.C., 11/09/2012)

"Cuando fue el juicio, claro, el primer día estuvimos presentes, acompañando a la familia. Yo, primera vez que iba a un juicio, la verdad es que estaba atónita, no... Lo único que estaba al lado de la familia, como un familiar más acompañando...". (M.C., $11 / 09 / 2012)$

- La organización de actividades específicas dentro del ámbito institucional para "curar" el miedo, para hablar el tema ante el reconocimiento de que la única salida y herramienta del educador es la palabra.

"Nosotros vivíamos con emergencias todos los días en el instituto, entonces, decidimos con Rebeca, que íbamos a hacer una misa. Lo hablamos al Padre Jorge [...] y le pedí por favor que nos ayude, que ya no sabíamos qué hacer, que en todo caso después íbamos a invitar a un pastor, si es que había problema con alguno de los chicos". (M.C., $11 / 09 / 2012)$

"También ahí en el patio de la escuela [...] hubo reuniones con toda la institución. Habló la hermana, hablé yo y ahí era que yo les decía a los chicos que se cuiden, que se cuiden entre ellos, que si ven una relación así lo denuncien a la familia, a la institución, a donde sea...". (M.C., 11/09/2012)

Los docentes, T.S. y B.S., se involucraron en las siguientes acciones:

"¿Qué es lo que se puede hacer desde mi lugar como docente? Entonces a mí se me ocurrió invitarla a Graciela Agüero, ella junto con una jueza o una abogada, mucho tiempo dictaron cursos de violencia, violencia de género. [...] Entonces acordamos el día y horario y se hizo eso para alumnos del Profesorado de Inglés, principalmente para sus compañeros, los alumnos de $4^{\circ}$ año y también el resto de los cursos del Profesorado...". (T.S., 09/08/2013) 
"...una alumna practicante, [...] organizó ella para toda la carrera de Bibliotecario y fue algo así como una jornada, invitó a varios disertantes del Hospital. Yo recuerdo que había invitado a un médico, a un especialista en esta temática que trata a pacientes con esto..., no sé cómo sería el nombre desde el punto de vista médico, pero personas para interpretar o para entender por qué actúa una persona así y cómo percibir, por ejemplo, personas que son agresivas. Eso también estuvo muy bueno porque fue una charla que arrancó a las $6: 30 \mathrm{~h}$ y terminó a las 11: $30 \mathrm{~h}$ de la noche. Los chicos preguntaban, se asesoraban...". (T.S., 09/08/2013)

"¿Qué hizo? Fue esa urgencia de unirnos de ir a la marcha de sentirlo así como la pérdida de un ser querido [...] ¿Y qué más? Creo que hay personas que fueron a los medios de comunicación. Me sorprendió cuando íbamos en las marchas que se hicieron -no sé cuántas fueron-, el aplauso, así, espontáneo, también las voces que se lanzaban en la comisaría donde sabía que estaba el responsable de este crimen". (B.S., 15/08/2013)

- Además, el proceso de implicación comprendió también la búsqueda de respuestas en los estudiantes cercanos a la víctima, y la comprensión de la ansiedad de estos, sus miedos y angustias:

"...después cuando yo hablaba con las chicas y les decía, pero ustedes estaban siempre juntas con Maira, ¿viste? ¿Qué hicieron ustedes...?". (M.C., 11/09/2012)

"S.N.S.: -¿Por qué fuiste a la primera audiencia?

R.G.: -Me invitaron los familiares de ella, porque la que tomó la posta fue la hermana de ella. Fui [...] a verle la cara a él, quería ver a ver qué hacía, qué actitud tenía, de arrepentimiento o algo, quería ver, uno trata de encontrar explicaciones siempre...". (R.G., 26/08/2013)

"Y yo le decía a los chicos: "Tratemos de esperar un poquito a ver qué nos dice la Justicia, no nos apuremos tanto, acordáte que ellos tienen que buscar muchas pruebas para estar seguros después en el juicio y todo lo demás". Yo me di cuenta que capaz estábamos apurados, muy ansiosos, pero bueno, la situación se daba, ¿no?". (M.C., 11/09/2012)

- Una vez resuelto el caso, con la culminación del juicio y la condena del culpable, el reconocimiento a la estudiante, en la entrega del certificado póstumo por los estudios que cursaba:

"Cuando ella cumple el año, se le dio el certificado a la familia como que ella ha terminado el Inglés, el Profesorado, un certificado...". (M.C., 11/09/2012)

- El reconocimiento de que seguramente hubo y habrá críticas, distintas opiniones o valoraciones respecto del rol que la institución y sus actores desempeñaron en ese momento: 
"Y bueno, alguien seguramente habrá quedado disconforme con la institución. La familia te aseguro que no, porque lo que ellos dicen...". (M.C., 11/09/2012)

- La afirmación de que el ciclo iniciado por la institución en la contención ante una situación particularmente dolorosa y escabrosa no se ha cerrado, sino que se mantiene vigente cíclicamente en gestos y ritos de ejercicio de memoria y toma de conciencia reiterados:

"Y después las misas que se siguen dando, creo que se siguen dando". (M.C., $11 / 09 / 2012)$

"Todos los meses hacíamos misas y las seguimos recordando, todos los aniversarios de su muerte hacemos un minuto de silencio, nos reunimos todos en el salón interno, les explico por qué porque hay muchos chicos que ya no saben de eso... A pesar de que hayan pasado varios años seguimos recordándola...". (R.G., 26/08/2013)

¿Para qué sirvieron las estrategias de implicación desplegadas desde lo escolar? En este punto bien cabe recordar la respuesta que Regis Debray formula sobre la utilidad de las instituciones: no nos sirven para nada utilitario, sirven por su propia perennidad, por su inclusividad y su anclaje a largo plazo, "Una pizca de inmortalidad entre la gente de paso que somos" (Debray, 2007: 8). Las instituciones, en especial las educativas, se nos presentan como instancias histórico-sociales y, a la vez, como instancias singulares de prácticas, tareas e interacciones en las que los sujetos intervienen, se vinculan, constituyéndolas. Las instituciones borran la individualización en términos de pensar y actuar por sí mismo para pensar y conducirse según un modelo "común". "Instituir" es asignar una esencia, es significarle al sujeto lo que es, es imponer un derecho de ser que es un deber ser (Garay, 1993). De allí la importancia de las instituciones: re-orientar la actuación, suministrar contextos y motivaciones sociales para comprender y darle sentido a la experiencia.

Tal vez la clave del rol de las instituciones ante el horror fue señalada por M.C. como al pasar:

“...y siempre estábamos presentes y los chicos, los compañeros de ella sobre todo, estaban muy presentes. Y los profesores hablaron con los alumnos, yo en alguna oportunidad hablé con los profesores para pedirles que colaboren, que hablen con los chicos, si los chicos tienen necesidad de hablar que suspendan las clases propias de la materia y que se hable, que se hable, que se hable, que se hable mucho del tema que es la única arma que tenemos nosotros: el diálogo, no tenemos otra...". (M.C., 11/09/2012)

Reconstruir el vínculo, no temer al ridículo, según expresión de Estanislao Antelo, crear las condiciones para el diálogo, operar sobre los efectos dispersivos (Correa, 2008), hacer posible la conexión y la redefinición de códigos que trasciendan los 
personalismos instituyendo solidaridad, sentido, constancia, asidero, en un medio saturado, pero maleable a nuestra práctica e imaginación.

Las prácticas que los distintos actores institucionales pusieron en juego ante el crimen cometido contra uno de sus miembros evidenciaron su potencial creativo y la resignificación de lo acontecido en el marco de lo cotidiano, dentro del entretejido de relaciones internas y externas de los diversos miembros de la institución. Estas prácticas -que comprometieron física, simbólica y subjetivamente la experiencia de los sujetosse plasman en el discurso de M.C. y adquieren una dimensión reflexiva y evaluativa, dando cuenta de los aspectos relacionales y transicionales del sujeto y sus entornos institucionales, construyendo su identidad en articulación, contraste e implicación.

\section{Palabras finales}

El análisis esbozado en estas líneas dista de agotar la riqueza múltiple, polifónica y relacional del discurso de los miembros de la institución educativa. La desmesura del crimen, que es piedra de toque para la indagación de las estrategias de que se valen las instituciones educativas a través de sus actores, desborda los márgenes teóricos establecidos y llama a un abordaje más amplio y detenido.

No obstante este primer acercamiento a la comprensión de las estrategias de implicación desplegadas por las instituciones educativas a través de sus actores nos permitió dar cuenta de su magnitud y relevancia. La institución "se puso al hombro" la situación, se hizo cargo del horror y salió a las calles, acompañó a los familiares, se presentó en los tribunales, organizó marchas, irrumpió en ámbitos ajenos a lo específicamente escolar, instituyó una presencia activa tendiente a paliar el daño que el crimen había provocado en su seno.

Por último, los ribetes y detalles del caso se presentan a la mente que analiza como una paradoja cruentamente simbólica: desmembrar para ocultar el cuerpo deviene en la evidencia fáctica de su localización y exposición pública y mediática. ¿Cuánto deseo y placer puede experimentar la mente asesina para exponer la obra de sus desbordes en tres puntos ¿equidistantes? de la ciudad? ¿Qué nos dice y qué suscita el cuerpo desmembrado de Maira, como para que las imágenes captadas por la policía en el operativo de "unión del cuerpo" hayan circulado por semanas en los celulares de cientos de vecinos? ¿Cómo despertar y continuar con la función educativa, cuando el crimen fue tan cercano y caló tan hondo en la comunidad? Estos y muchos otros interrogantes pueden plantearse para el abordaje de futuras investigaciones que nos permitan profundizar el análisis de las prácticas institucionales desde un punto de vista multidisciplinar. 


\section{Agradecimientos}

A Stella Maris Curi, ejemplo y guía permanente. A Mirian Cano, Rebeca Galperín, Beatriz Saunig y Tony Stakul, docentes, más allá del umbral del aula. A Zulma Parpinelli y Mariela González, futuras docentes.

\section{Notas}

[1] Se trata de un feminicidio que conmovió profundamente a la comunidad chaqueña. Maira Alejandra Tévez, de 21 años, fue asesinada el 9 de abril de 2010 en la ciudad de Presidencia Roque Sáenz Peña, Provincia del Chaco, Argentina. La mujer fue asesinada de un disparo de arma de fuego. Su cuerpo fue descuartizado. El culpable fue hallado, se trataba de su novio, Héctor Ponce, de 26 años. Los estudios forenses determinaron que "la muerte de la joven se produjo como consecuencia de un disparo de arma de fuego en la zona de la nuca. Partes de su cuerpo fueron encontradas en distintos lugares [de la ciudad]. Fuentes policiales indicaron que el autor del crimen habría pasado la noche con la víctima y el baño sería el escenario donde pudo haber puesto en práctica sus conocimientos en instrumental quirúrgico. El joven, en sede policial, admitió haberle disparado en la cabeza, para luego descuartizarla con cuchillos multiuso que fueron hallados en su domicilio particular, junto con restos de sangre y cabello. En sede judicial pidió nulidad de todo lo actuado y solo admitió que el arma se le disparó". El 5 de noviembre Héctor Ponce fue hallado culpable y condenado: "La Cámara Primera en lo Criminal condenó a prisión perpetua a Héctor Ponce, al considerarlo autor material del delito de "Homicidio agravado por alevosía" de Maira Tévez". También quedó probado que la decapitación se produjo cuando la joven aún mostraba signos vitales y el desmembramiento fue post mortem. Fuente: Diario Crisol, Chaco Síntesis, Chaco Primicias, Diario Norte. Informe de Investigación de Feminicidios en Argentina, Red Informativa de Mujeres de Argentina.

Información disponible en: http://www.rimaweb.com.ar/articulos/2011/informe-deinvestigacion-de-femicidios-en-argentina/

[2] Para este estudio se realizaron un total de seis entrevistas: a dos autoridades de la Institución educativa - la ex rectora, Mirian Cano, la ex vice rectora y actual rectora, Rebeca Galperín; a dos docentes, Beatriz Saunig y Antonio Stakul, y a dos estudiantes, Zulma Parpinelli y Mariela González. Durante el desarrollo del trabajo cada uno de ellos será referido a través de las iniciales de sus nombres: M.C., R.G., B.S., A.S., Z.P. y M.G. Para la citación de fragmentos de sus discursos se utilizarán las iniciales del nombre y la fecha de la entrevista.

[3] Mirian Cano, profesora en Ciencias de la Educación, egresada de la Universidad Nacional de Catamarca, es oriunda de esa ciudad. No obstante, reside en Pcia. R. Sáenz Peña, Chaco desde la década del 80, lugar donde formó su familia y habita actualmente. 
[4] El lugar del intercambio tuvo lugar en la vivienda de M.C., entre las 10:00 h y las 11:30 h del 11 de septiembre de 2012. La entrevista fue grabada en su totalidad y desgrabada posteriormente a efectos del análisis.

[5] Instituto de Nivel Terciario "Juan Mantovani" a continuación: INTJM. Fundado en 1975 como Instituto Superior de Formación Docente "Mariano Moreno". Tradicionalmente fue la mayor institución formadora de maestros de nivel primario e inicial del centro de la provincia del Chaco. En 1989 cambió su nombre (Res. N ${ }^{\circ}$ 279/88 del CGE) por el que actualmente detenta. Desde 1999, en su sede se dictan varios profesorados para el nivel secundario: en Inglés, en Tecnología, en Psicología. No posee edificio propio por lo que funciona en la planta alta de la EET № 22 "Tte. Benjamín Matienzo" en el casco céntrico de Pcia. R. Sáenz Peña. Información disponible en:

http://ispmantovani.cha.infd.edu.ar/sitio/index.cgi?wid seccion=1\&wid item $=9$

[6] Maira Alejandra Tévez, a continuación M.T., era una estudiante de $4^{\circ}$ año del Profesorado en Inglés. Oriunda de la ciudad de Pampa del Infierno, era la hija menor de una familia modesta. De carácter afable y resuelto, era líder al interior de su grupo de pares. Sus profesores la identificaban por ser una alumna destacada por su desempeño académico. Según versiones de sus allegados y familiares se había relacionado afectivamente hacía poco menos de un año con Héctor "Nano" Ponce, su asesino. La noticia de esta relación no fue bien recibida por el entorno familiar ni por los amigos de la víctima, por considerar inapropiadas ciertas conductas de este sujeto. El padre de Maira Tévez, por ejemplo, no deseaba recibirlo puesto que lo acusaba de haberle sustraído su teléfono móvil en la única visita que hizo a su hogar en diciembre de 2009. Las amigas de Maira relataron a su vez que en varias ocasiones debieron prestarle dinero a Maira para pagar el alquiler de la pensión y sospechaban que Ponce se lo quitaba, por lo que semanas previas al asesinato habían compelido a Maira para que terminara la relación que la unía a Ponce.

[7] Silvia N. Sánchez, a continuación S.N.S.

[8] Ambas compartieron actividades como capacitadoras en 2006 y 2007. Además, la entrevistadora se desempeñó como docente en el Instituto Terciario en el cual Mirian Cano fue rectora. Al momento del registro de la entrevista no compartían una labor cotidiana, ni se frecuentaban, pero mantenían una relación amable, tanto en ámbitos informales como formales.

[9] Si bien Miriam Cano reside en Pcia. R. Sáenz Peña desde la década de 80, es oriunda de Catamarca, ciudad en la viven algunos de sus familiares y amigos, y a la que retorna con frecuencia. Durante la entrevista manifestó que conoce a los familiares de María Soledad Morales, joven que fue víctima de feminicidio en la década del 90; y que es amiga personal de Marta Pelloni, religiosa que tuvo un papel protagónico en la lucha contra la impunidad en ese emblemático caso.

[10] El énfasis indicado gráficamente con negrita fue de la entrevistada. 
[11] El subrayado es de la entrevistadora.

\section{Referencias bibliográficas}

-Barrancos, D. (2007). Mujeres en la sociedad argentina. Una historia de cinco siglos. Buenos Aires: Sudamericana.

-Correa, C. (2008). Pedagogía y comunicación en la era del aburrimiento en Pedagogía del aburrido. Buenos Aires: Paidós.

-Chouliaraki, L. y Fairclough, N. (1999). Discourse in late Modernity. Rethinking Critical Discourse Analysis. Edinburgh/Cambridge: Edinburgh University Press. (Traducción de Sara Isabel Pérez).

-Eggins, S. y Martín, J. R. (2003). Géneros y registros del discurso en van Dijk, Teun A. (comp.) El discurso como estructura y proceso. Estudios sobre el discurso I. Una introducción multidisciplinaria. Barcelona: Gedisa.

-Enríquez, E. (2002). La institución y las organizaciones en la educación y la formación. Buenos Aires: Coedición: Ediciones Novedades Educativas y Universidad Nacional de Buenos Aires.

-Fairclough, N. (1992). Discourse and social change. London-New York:

Routledge.

-Fernández, M. L. (2002). "La institución y las organizaciones en la educación y la formación de Eugene Enríquez. Acerca de la búsqueda afanosa de la institución y la persona". En Enríquez, E. (2002), óp. cit. (Prólogo).

-Garay, L. (1993). La cuestión institucional de la educación y las escuelas. Conceptos y reflexiones en Butelman, I. (comp.). Pensando las instituciones. Sobre teorías y prácticas en educación. Buenos Aires: Paidós.

-Ghio, E. y Fernández, M. (2005). Manual de Lingüística Sistémico-Funcional. El enfoque de M. A. K. Halliday y R. Hasan. Aplicaciones a la lengua española. Santa Fe, Argentina: Ediciones UNL.

-Halliday, M. (1978). El lenguaje como semiótica social. México: Fondo de Cultura Económica.

-Laclau, E. y Mouffe, C. (2004). Hegemonía y estrategia socialista. Hacia una radicalización de la democracia. México: Fondo de Cultura Económica.

-Loureau, R. (1975). El análisis institucional. Buenos Aires: Amorrortu.

-Lobato, M. Z. (2007). Historia de las trabajadoras en la Argentina (1869-1960). Buenos Aires: Edhasa.

-Montemayor-Borsinger, A. (2009). Tema. Una perspectiva funcional de la organización del discurso. Buenos Aires: Eudeba.

-Souto, M. (1993). Acerca de incertidumbre y búsquedas en el campo institucional en Butelman, I. (comp.). Pensando las instituciones. Sobre teorías y prácticas en educación. Buenos Aires: Paidós. 
-Volóshinov, V. (2009). El marxismo y la filosofía del lenguaje (prólogo y traducción de Tatiana Bubnova). Buenos Aires: Ediciones Godot.

\section{Referencias electrónicas}

-Debray, R. (2007). Transmitir más, comunicar menos. A Parte Rey Revista de Filosofía Nº 50, Marzo de 2007. Disponible en http://serbal.pntic.mec.es/AParteRei

-Ponzio, A. (2003). Escritura de la novela y del cine como crítica de la comunicación global. Revista Signa número 15: UNED. Disponible en:

http://dialnet.unirioja.es/descarga/articulo/1455822.pdf

-Rico, A. B. (directora) (2010). Informe de Investigación de Feminicidios en Argentina (1 de enero al 31 de diciembre de 2010). Observatorio de feminicidios en Argentina de la Sociedad Civil "Adriana Marisel Zambrano". Red Informativa de Mujeres de Argentina. Extraído el 10 de febrero de 2013.

Disponible en http://www.rimaweb.com.ar/articulos/2011/informe-de-investigacion-defemicidios-en-argentina/ 